\title{
Developing a Network of Community Health Workers: Improving the Lives of Migrant Farmworkers
}

\author{
María Isabel Ortega-Vélez ${ }^{*}$, Cecilia Rosales ${ }^{2}$, Patricia Aranda Gallegos ${ }^{3}$, \\ Alma Delia Contreras Paniagua', Luis Valdez², Jill De Zapien² \\ ${ }^{1}$ Centro de Investigación en Alimentación y Desarrollo, A.C. División de Nutrición, Hermosillo, Mexico \\ ${ }^{2} \mathrm{Mel}$ and Enid Zuckerman College of Public Health, University of Arizona, Tucson, USA \\ ${ }^{3}$ El Colegio de Sonora, Centro de Estudios en Salud y Sociedad, Hermosillo, Mexico \\ Email: ‘iortega@ciad.mx, crosales@email.arizona.edu,pag@colson.edu.mx, acontreras@ciad.mx, jolitrac@email.arizona.edu, \\ dezapien@email.arizona.edu
}

How to cite this paper: Ortega-Vélez, M.I., Rosales, C., Gallegos, P.A., Paniagua, A.D.C., Valdez, L. and De Zapien, J. (2016) Developing a Network of Community Health Workers: Improving the Lives of Migrant Farmworkers. Open Journal of Social Sciences, 4 , 140-154.

http://dx.doi.org/10.4236/jss.2016.410011

Received: September 15, 2016

Accepted: October 24, 2016

Published: October 27, 2016

Copyright (c) 2016 by authors and Scientific Research Publishing Inc. This work is licensed under the Creative Commons Attribution-NonCommercial International License (CC BY-NC 4.0).

http://creativecommons.org/licenses/by-nc/4.0/

\begin{abstract}
One of the main strengths of today's global food system is the labor force. Within emergent countries, farmworkers are an important element of competitiveness. However, food production that frequently stands in developed countries family tables rests upon the usually precarious living and health conditions of farmworkers, especially those that should migrate from regions that are far from the agribusiness where they work and live most of the year. Furthermore, healthcare becomes a challenging task because of cultural, socioeconomic and ethnic barriers. The aim of this study was to develop and evaluate a Community Health Worker (CHW) training model among agricultural Mexican migrant farmworkers, focusing on strengthening a health prevention environment conducive to improve health. This was a qualitative action-driven research carried out in southern Mexico communities as well as at northwest Mexico agribusiness. The project was implemented in four stages: needs assessment, curriculum design, training and implementation and process evaluation. The socioecological model guided our methodological and analytical process; we followed a Community Based Participatory Approach (CBPA) to interview and train a network of $40 \mathrm{CHW}$. Results showed that CHW's main health priorities were dehydration and heat stroke, respiratory infections, gastrointestinal infections, work accidents, hygiene, nutrition, as well as mental health including substance abuse and depression. Training evaluation 1) improved communication between middle management and migrant farmworkers, as well as between middle management and farm administrators, 2) increased middle management consciousness about farmworkers health needs and responsibility, and 3) increased awareness about how improving the environment could help prevent diseases.
\end{abstract}




\section{Keywords}

Community Health Worker (CHW), Farmworkers, Migration

\section{Introduction}

Health promotion and disease prevention are vital to the improvement of overall health of all populations regardless of socioeconomic status, political affiliation, and sociocultural background and most importantly are critical to the health and well-being of migrant farmworkers [1]-[3]. Agricultural business in northern Mexico, especially fruit and vegetable production, are immersed in the globalized food system, largely exporting to North America, Europe and Asia. Despite being essential to the food production chain, migrant farmworkers have high rates of occupational health risks. These risks are compounded by limited access and lack of continuity of care, and no access to preventive care due to cyclical migration and low retention of health workers in the field and at home, especially in rural communities [4]. Migrant farmworkers, who travel annually throughout Mexico to work at private agribusiness, are often one of the most marginalized populations and have the greatest need of access to care and health promotion and disease prevention programs. This population is subject to many job-related occupational health hazards, as well as communicable and non-communicable diseases. Due to the complexities of providing care to a transient population, migrant farmworkers need an integrated health care model that reflects community-level participation, as well as context-related health issues management and training. Community health worker $(\mathrm{CHW})$ models focusing on community-centered health promotion use a participatory approach to work within the community to develop leaders who can integrate and continually develop responsive health promotion methods.

\subsection{Farmworker Identification of Health Concerns}

Migrant farmworkers participate in strenuous tasks under the exposure of a wide variety of occupational risks and hazards. Depending on seasonal weather and agricultural market demand, the need for workers fluctuates throughout the year and rests heavily on the agricultural labor process phases: sowing, planting, weeding, pruning, harvesting, packaging, and agrochemical application [5]. Constant migration, living conditions, and health care availability further extend the complexity of the issues that migrant farmworkers face.

Common health risks include pesticide exposure, heat and sun exposure, injuries due to hazardous tools and machinery, infectious disease exposure, musculoskeletal injuries, respiratory illnesses, skin disorders, eye injuries, mixed with increasing risk factors for chronic disease, specifically, obesity and diabetes, chronic respiratory problems, dermatologic conditions, cancer, depression, tuberculosis, neurologic deficits, and higher rates of infertility and miscarriages [4] [6]. These are pervasive health risks that are preventable through increased availability and affordability of care, improved continu- 
ity of care and the integration of health promotion strategies [7]. In addition to the increased presence of occupational health hazards, as well as communicable and noncommunicable disease risks, it is imperative to understand the limits to access to care, as well as how best to address the social determinants of health in order to improve the health of this particular population. Migrant farmworkers who labor in rural communities are medically underserved primarily due to shortage and low retention rates of health providers [4]. Moreover, the health risks pervasive in the occupational environment are exacerbated, as supervisory staffs are sometimes inadequately trained to address on-site injuries or infirmity, especially when agribusinesses are experiencing shortages of onsite health providers [8].

Language, low literacy, low health literacy, and transportation needs create even more barriers to care. In Mexico, indigenous populations migrate primarily from the poorest and most southern states of Chiapas, Veracruz, Puebla, and Oaxaca for employment [9]. Most indigenous migrants speak little to no Spanish, have strong ties to their cultural background, and are often accustomed to traditional practices of health care and disease prevention. Indigenous groups, in particular, frequently follow the migrant agricultural streams from southern to northern Mexican states to earn a living. Factors contributing to migration include lack of employment, displacement, economic depression or instability in home communities, and the deterioration of physical environment [4] [6] [10]. In summary, internal migration of farmworkers, especially those traveling from southern and the poorest states in Mexico to northwestern states, require a health care delivery model that addresses the specific needs related to this mobile population that is subject to ever changing living and working conditions [4] [6].

\subsection{Specific Aims and Theoretical Framework and Approach}

\subsubsection{Specific Aim}

The specific aim of this study was to collaboratively develop and evaluate a $\mathrm{CHW}$ training model with agricultural Mexican migrant farmworkers, focusing on strengthening a health prevention environment in their communities of origin, as well as in their working communities in northwestern Mexico.

The Socioecological Model was the conceptual framework that guided us to understand the involvement of directives, middle managers, supervisors and farmworkers in the process of health promotion [11] [12]. This theoretical model also guided our research to understand the social determinants of health (farm health and dining services, cost of food, farm organization and model of health care, as well as cultural differences between owners, managers and farmworkers) that could impede or facilitate the process of training and its success. Finally, to identify the health promotion needs of farmworkers and the better strategies to develop a participative model development, we used a Community-Based Participatory Research (CBPR) approach [11]-[14].

\subsubsection{Community Based Participatory Research}

Community based participatory research (CBPR) is defined as "a collaborative, partnership approach to research that equitably involves, for example, community mem- 
bers, organizational representatives, and researchers in all aspects of the research process. Partners contribute their expertise and share responsibilities and ownership to increase the understanding of a given phenomenon, and incorporate the knowledge gained with action to enhance the health and well-being of community members" [13] [15]. CBPR is not a research method or a study design, but rather an approach that is intended to give the community equal decision making power in the research projecta form of community empowerment [16]. CHW's present an opening for community-based participatory research (CBPR) by their unique position as a bridge between researchers and the communities they study. As O'Brien et al. propose, "Community Health Workers can bring the end users' perspectives to academic investigators; successful programs often integrate feedback from communities to solve challenges that arise during implementation of CHW programs" [17]. Utilizing a CBPR approach provided the foundation for understanding all of those contextual issues and leadership styles surrounding the lives of farmworkers that would be vital to a successful health promotion training curriculum.

\subsection{Study Design and Location of Study Participants}

This was a qualitative action-driven research [18] carried out at southern Mexico communities (states of Puebla and Chiapas), as well as at northern Mexico farms (Don Enrique, La Cuesta y Pozo Manuel in the Municipality of Hermosillo, and San Miguel de Horcasitas, Sonora, Mexico) (Figure 1). The project was implemented in four stages: Needs assessment, curriculum design, training and implementation, and process evaluation (Figure 2). Needs assessments were conducted first, with 32 mid-level managers who had direct communication and responsibilities with the farmworkers within three large agricultural camps. Interviewees included agricultural engineers, farmworker, work crew supervisors, contractors, dinning managers, social workers and

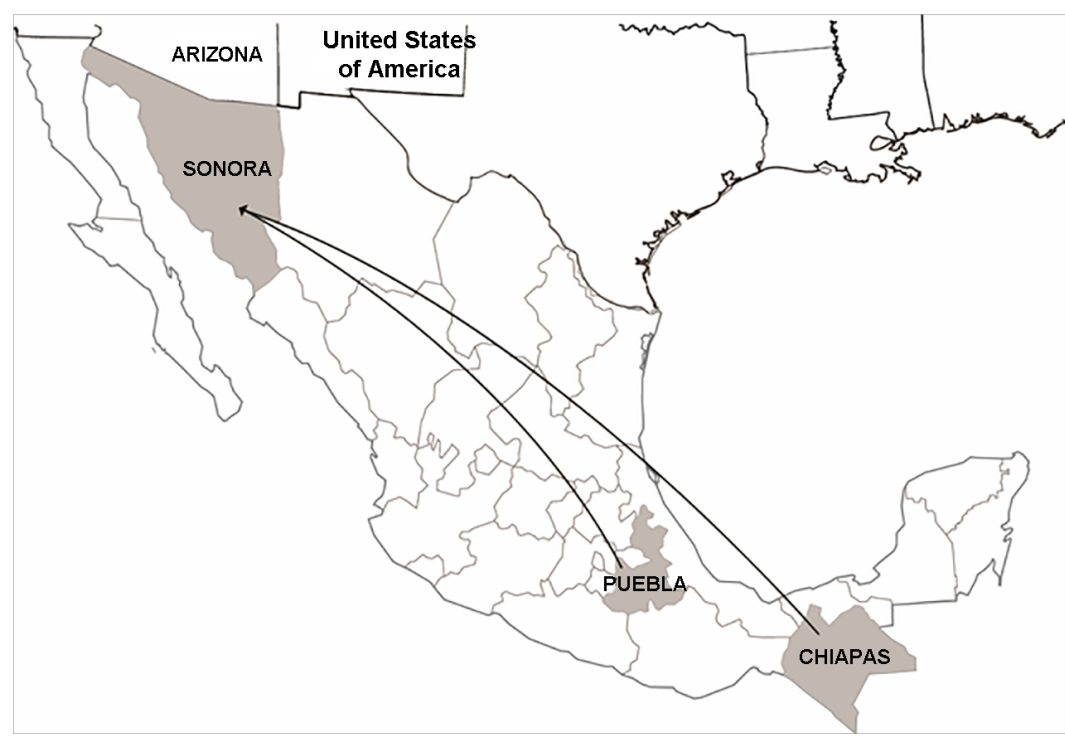

Figure 1. Geographical location of the study area. 
medical personnel (medical doctors, students, dentists) to illicit the most important health issues. Upon completion of this needs assessment, we conducted training with middle management, which focused on the health issues identified through the interview process on the three large farms where approximately 3200 migrant farmworkers were employed.

In order to develop and evaluate the curriculum with migrant farmworkers themselves, the second phase of the project included an additional needs assessment and training with 8 farmworker supervisors in their home communities (San Andres Larrainzar, Chiapas). Farmworkers supervisors came from the same communities than most farmworkers and speak their native language; in addition, they have learned Spanish throughout several working seasons at the agribusiness in northern Mexico. Then, they can communicate well with middle managers and their fellow farmworkers. The training of these supervisors as health promoters intends to enable the networking between farmworkers and middle managers to facilitate health prevention strategies. We again used a participatory popular education approach and group interviews to identify the main health concerns among farmworkers [18]-[20].

\subsubsection{Training}

Trainings were largely focused on themes that are critical to a farmworker based health promoter program including dehydration and heat stroke, respiratory infections, intestinal infections, work accidents, hygiene, nutrition, as well as mental health including substance abuse and depression (Table 1).

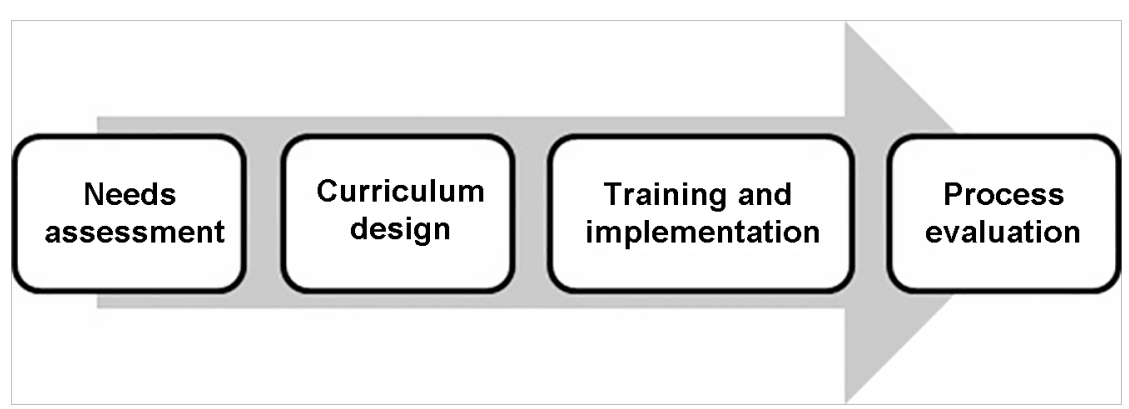

Figure 2. Process of training development.

Table 1. Course description.

Course Contents

What is a Health Promoter?

Dehydration and diarrhea

Heat stroke

Respiratory diseases (flu, sore throat, fever)

Accidents

Nutrition

General hygiene

Mental health
- Characteristics

- Responsibility and compromise

- Identification

- Prevention

- Treatment 
Communication skills and transfer of health information was also central to each training session. All the training included interactive activities and role-playing, and was based on real world experiences that had taken place in the living and working environments of workers. Action simulations provided tools for specific prevention messages, how to react to immediate emergencies and provide the role of being the liaison between a particular health situation and the staff at the nearest Health Clinic. Throughout the training sessions we used sociodramas (role play), fotonovelas (photo novels), and group dynamics; we also developed a training manual, a quick health aid guide and a memory game that helped to collect $\mathrm{CHW}$ insights and reinforced training content. Materials can be found at: http://sitios.colson.edu.mx/nosotrossanos/.

\subsubsection{Program Evaluation}

We conducted the evaluation of the curriculum during the following agricultural peak season when workers returned to the agricultural camps. We conducted 5 individual and 3 group interviews with field supervisors from Chiapas and middle management workers that are permanently stationed in the agricultural camps in Sonora (26 participants in three groups of 8,6 and 12 persons, see (Table 2).

Our multidisciplinary team collaboratively developed an interview guide based on best practices of qualitative inquiry with agricultural workers and CHW-based program evaluation. The interview guide was composed of 11 open-ended questions (Table 3) which elicited their perceptions regarding their role as a $\mathrm{CHW}$, the adequacy and utilization of their training, as well as suggestions for program improvement. The project was exempt from Human Subjects Review as it was classified as a program evaluation for quality improvement by the Institutional Review Boards of all of academic institutions involved.

Table 2. Participants in the evaluation stage per type of farm occupation.

\begin{tabular}{ccc}
\hline $\begin{array}{c}\text { Farm 1 } \\
\mathrm{n}=8\end{array}$ & $\begin{array}{c}\text { Farm 2 } \\
\mathrm{n}=6\end{array}$ & $\begin{array}{c}\text { Farm } 3 \\
\mathrm{n}=12\end{array}$ \\
\hline Foreman & Foreman & Production unity manager \\
Medical intern & Food safety supervisor & Production coordinator \\
Social worker & Camper & Production improvement assistant \\
Food safety supervisor & Dinner Manager & Agricultural Engineer \\
Manager & Administrative secretary & Record keeper \\
Vegetable farmworker & Social worker & Production aid \\
Agricultural intern & & Storer \\
& & Group supervisor \\
& & Storer assistant \\
& & Food safety technician \\
& & Irrigation system assistant \\
\hline
\end{tabular}


Table 3. Evaluation interview guide questions.

\section{Questions}

1) What type of training did you attended as health promoter? (Include type and number of training sessions).

2) Can you describe your experience as health promoter, according to the following?

a) Your own experience,

b) Your family' experience,

c) Your experience when working at the farm?

3) Which training themes have been more important to you as health promoter?

a) Can you share how did you use that information in a specific situation?

4) What was more useful to you, your family, in your community and with your co-workers?

5) Which training themes have been more utilized in your own experience?

6) In your own experience, are there training themes that were not useful? Why?

7) Are there any other health themes that we should consider in the training sessions? Which ones?

8) Are you confident on your role as health promoter? How?

9) Have you felt that your work as health promoter has been recognized by your employer?

10) What problems have you faced when trying to implement your training as health promoter?

11) Do you have additional comments on your experience as health promoter?

\subsubsection{Data Analysis}

All interviews were conducted in Spanish. Interviews were audio recorded and successively transcribed verbatim by members of the research team. Grounded in a deductive process [18], a preliminary codebook was developed based on the interview guides and the primary aims of this study. In addition to the deductive codes, a thematic analysis of the data led to the supplementation of the codebook with themes that emerged throughout assessment of the transcripts.

\section{Results}

Findings indicate that there were a variety of positive impacts that occurred as a direct result of the health promotion training. We organized the themes that we identified in the data into three overarching categories: 1) the relationship between the health promoter and the working community, 2) the importance of prevention, and 3) the perceived power of knowledge. We present these themes and our analysis of the data below and use the words of the participants whenever possible to provide a contextual illustration of their meaning.

\subsection{The Relationship between the Health Promoter and the Working Community}

Findings indicate that trainings have had a positive impact on the relationship between curriculum-trained middle management workers, supervisors and farmworkers. Participants mentioned that they perceive improved relationship to be a direct result of the development of better communication between middle management and farmworkers. They also stated that the increase in communication manifested into increased trusting relationships between them and the working community. Moreover, they perceive that farmworkers recognize them as someone that can offer assistance when necessary and 
especially during an emergency situation. The elevated presence of communication and trust can lead to potential earlier detection of high risk situations that may have a negative impact on the health of individual workers as well as the working community at large.

"We have built trust among farmworkers, for them to identify us, so if something happens they know whom they can approach for help".

"Acknowledgement come now from people... they know who can help them now"

"People come now to us when there is a cut" "People acknowledge us (promoters) as those that can help them" "They (farmworkers) ask us questions... and now we have confidence on communicating them what we have learned" "Now we can have better interaction with people, so we can better detect what is happening to them" "Now we can begin to have a connection with people".

\subsection{The Importance of Prevention}

Findings also indicated that participants had a rich understanding of the need to take the necessary preventive measures to protect the wellbeing of the working community. Participants mentioned that the most important thing they learned as a result of the workshops was the importance of detecting the early signs and symptoms of an impending emergency in order to take the appropriate measures.

"Most important thing I have learned is as I said, from the beginning, TO PREVENT... That is the strongest issue that they have showed us, to notice what is happening to those that have fainted, the symptoms that they can have..."

"To prevent and to detect when somebody is fainting... the degree... how to say it... how to be aware that somebody is getting dehydrated, ok? What are the symptoms... if shel he is sweating too much".

\subsection{The Perceived Power of Knowledge}

Participants declared that as a result of the knowledge acquired, they feel an elevated level of comfort and trust in their reaction to any situation that could potentially be harmful. Moreover, participants noted that they feel accountability to the workers to ensure that they put their knowledge into practice. Participants feel a responsibility to continue learning, to share information, and to take action when deemed necessary.

"The fact of knowing what we know now lays an obligation and responsibility on $u s$ ". "Now we feel more secure on how to do some things... before we cleaned cuts with oxygenated water... now we know we should do it just with clean water and soap".

"Now we do not wait for somebody who knows what to do (in an emergency), now we feel capable to do something" "We feel a different commitment ... we have attended training courses and we now have a different knowledge. "The commitment of being a health promoter is that we feel that we can save a life, just by acting, just by helping". 
Throughout the process of interviewing and training, middle management accomplished three main aspects that would be central to a CHW networking within the farms: 1) improving communication among middle management and migrant farmworkers, as well as between middle management and farm administrators, 2) increase middle management consciousness about farmworkers health needs and responsibility and 3) increase awareness about how improving the environment could help prevent diseases. Regarding farmworkers supervisors, or field supervisors, the CHW training in their communities of origin revealed that participation and discussion of health prevention issues within migrant workers own physical and cultural context, can increase the trainee's participation; also, that discussion of barriers to health promotion that they encountered in their own communities, as well as when traveling to the farms in northwestern Mexico, or at the farms, allowed a better understanding of farmworkers' disease risk. On the other hand, impact evaluation showed that one of the main barriers CHWs (middle management) will find when working with migrant farmworkers is language, since most of the farmworkers coming from Chiapas speak their indigenous language, being Totzil or Tzetzal. However, training of indigenous field supervisors would enhance CHW networking efforts, since all of them (8) speak Spanish as well as Totzil or Tzetzal.

\section{Discussion}

Our findings indicate that there are benefits to a CHW-based health promotion program in agricultural work. The program resulted in an improved relationship between middle management and farmworkers. We also saw that there was an increased awareness of responsibility for the health of the working population. Moreover, the findings show that the training equipped the participants with the adequate knowledge to manage agricultural work-bound health problems. Participants exhibited high health promotion skills and emergency preparedness self-efficacy, while recognizing that their knowledge and scope of work is limited, and at times the expertise of a health professional is warranted. As evident in our findings, the implementation of a CHW-based program in an agricultural environment has the potential to have a positive impact on the health and wellness of the working population. A well-trained, well-equipped, and well-supported CHW represents an imperative link between farmworkers and farm administration. The improvement of communication between $\mathrm{CHW}$-trained middle management and farmworkers supervisors increases the capability of adequately assessing the needs of the working population in ways that most farm administrations are currently incapable of. Moreover, building capacity for holding and sharing health related knowledge within marginalized communities has the potential to empower the working population to take control of their health. That is, the creation of a network of $\mathrm{CHW}$ that exists within working communities has the potential to have an exponential impact on the migrating working community as time goes on and prevention practices expand and share.

There were however, some limitations to the program. Participants mentioned that 
while their relationship with farmworkers improved as a result of their training, there were unmet gaps in communication with people who are not proficient in Spanish. Around a third of workers each season (from around 3000 workers/per season) do not speak Spanish, and may find themselves at a potentially vulnerable position. Lapses in communication due to language barriers especially when communicating health related information or in relation to help seeking behaviors, may put this segment at a disproportionally elevated risk relative to their Spanish-speaking counterparts. However, the identification of this gap can lead to the training of groups of CHW who adequately represent the demographic characteristics of the population. This in turn may potentially trigger an even larger impact on the working communities both within the farms and their home communities.

Moreover, although there initially was a positive movement toward a wide integration of this promotion program, its success requires the participation of all levels of the agricultural hierarchy. It is evident from our findings that the health promoters are enthusiastically absorbing the material and putting their knowledge to practice, however, if the program is not fully integrated into the administrative plan and supported by all levels of farm management and corporate administration, it will eventually disintegrate. A community-level program like this requires adequate acknowledgement and support by administration via continuation of training, administrative recognition of promoter training and labor. Previous research indicates that farm owners and administrators are aware that social responsibility actions towards their workers and neighbor communities could mean a positive impact to their business [21]; as such, health promotion could be a first impact strategy conducive to improve workers' human development.

Community Health Worker ( $\mathrm{CHW}$ ) programs are, in many cases, the frontline for primary care and disease prevention. CHW identify members of the population to be the liaisons in delivery of care, and health promotion. These members of the community are able to overcome cultural and linguistic barriers, and relate directly to the migrating farmworkers. CHW can also work to identify, understand and overcome other barriers, including health beliefs, appropriate models for providing health care, financial limitations, and overall health literacy. CHWs can provide a bridge of communication between the needs of the population and, specifically in agriculture, the expectations and attitude of the grower and health care staff, to create lasting change in the provision of health services to marginalized populations. CHW can fulfill the role of assessment, community building, and monitoring to help marginalized populations overcome barriers to access, and limit exposure to preventive health problems and preventable disease [6] [17].

Although CHWs serve as the front line representatives for health promotion with migrant populations, the extensive challenges they face, with both community participation and their access to communities that might be most in need, should be noted. First, to successfully implement a community health worker program, community participation requires that healthcare providers have a solid knowledge base of the community they are working with and have training in cultural sensitivity, communication 
skills and conflict management. While these are all assets that complement the skills and competencies of CHWs, they can become barriers if they are not also found in the health providers [22]. Second, there are barriers for the capacity building among CHWs based on community level participation. There can be barriers that lie within this framework dependent on social and personal contexts, specifically, if they are in any field of healthcare, including limited knowledge or preconceived ideas of the goals and objectives of the program. Challenges also occur upon the realization that change can be slow and that it requires continual integration, presence, patience, and goal orientation to successfully work with community members to enact positive change [22]. While it is imperative to address the challenges a $\mathrm{CHW}$ can face while providing services, continual community engagement, extensive knowledge of the culture and needs of the community one is trying to address, and high levels of patience, trust-building skills and a knowledge base of the health risks the community faces, can all be indicators for positive change and capacity building for a community health worker program. $\mathrm{CHW}$ can serve as not only the front line health providers, but also can facilitate change through addressing needs and challenges within a population, and offer insight and communication to community members to bring awareness to the needs of special segments of the population [17].

Balcazar et al. (2011) insists that lay health promoters represent a workforce increasingly recognized as a force for reducing health disparities by providing culturally appropriate health education and other services. Quandt et al. (2013) showed through a carefully designed evaluation of interviews with 610 farmworkers families, that lay health promoter-led educational programs can achieve significant changes in knowledge in hard-to-reach, minority, immigrant populations. Balcazar brings to light the consequences of a narrowly defined CHW intervention that "could not capture the intangible impact of building individual and community capacity, which encompasses opportunities for strengthening social support, building relationships to support self-help, increasing access to resources, developing social capital, and producing changes in power relationships". Qualitative inquiry and theoretical frameworks such as that of a socioecological model, can increase understanding of underlined causes of behaviors and human relationships; this is particularly important when working with migrant populations living in poverty and with a particular view of health risks and treatments, shaped by cultural and language differences.

Beyond the immediate characteristics of a community health worker program it is important to discuss the broader elements needed for truly successful health promotion programs. Among those elements of a successful health promotion program according to Green \& Kreuter (1991), is to address those health problems that correspond with the epidemiological profile of a given population, as well as those issues that the population itself considers a priority. As such, one element of a successful health promoter's model must address those needs prioritized by workers at all levels of the organization-middle management, field supervisors and farmworkers. In this way, the CHW approach is strengthened by participation of middle management and field supervisors 
in defining and discussing main health themes for the training curriculum. As the socioecological model and the health pyramid approach recognizes, health education or health promotion would not have an impact on health outcomes if there are environmental barriers that limit people to act on their behavior changes to improve health.

Community organization. One of the main challenges encountered in the training process was the vertical and authoritarian farm culture. The traditional work style followed more biomedical treatment measures to health management instead of a health promotion approach. Participation of the Farm's Health Team in the training process was essential to overcome this barrier. We encouraged recognizing the promoter activities as part of the health team's efforts to minimize health problems and maximize the use of resources, which is aligned with the business/farm goals.

\section{Conclusions}

\section{Practical Implications and Public Policy Recommendations}

A Health Promotion Program based on a network of health promoters among migrant farmworkers will only be successful in improving the health of farmworkers and their families if training is participatory and continually involving personnel from all working levels of the workforce, and goes beyond specific health conditions to address the improvement of the environmental working and living conditions of the farms.

The health promotor model for migrant farmworkers requires a long term commitment from agribusiness to be sustainable. Research has shown that in general, Corporate Social Responsibility (CSR) among Mexican agribusiness in Sonora is classified, according to Quazi and O’Brien, as a classical and reduced view yet, CSR is frequently known as a central aspect in business management beyond social, environmental and human rights issues, to elucidate and legitimate businesses role in poverty reduction [23]. Nevertheless, since most agribusiness in northern Mexico behave as private enterprises, and consequently management and organization rules are internally defined, we see agribusiness involvement as a critical factor to the health promoter's model adoption and success. In this study, agribusiness involvement has been a key factor in the development and implementation of the model. Achieving model adoption and replication at a national level will be a challenge that would be achieved only through proper diffusion of results, not only regarding publications, but also through real model transference, including its successes and difficulties. Agribusiness' associations, governmental associations (Social Development Secretariat, Health Secretariat), as well as binational health promotion associations (Research Program on Migration and Health, PIMSA) are key actors to model diffusion and promotion.

Health promotion activities require adequate environmental conditions. According to the WHO document on Social Determinants of Health and the social-ecological perspective of health promotion, essential aspects of any health promotion program should take into account socioeconomic, environmental and cultural aspects that are mediators of behavioral changes aimed to healthy lifestyles. These conceptual approaches insist that an interaction of environmental, personal, institutional and com- 
munity factors are needed to motivate changes conducive to health improvement [12] [24]. In addition, Thomas R. Frieden (2010) points out that health education impact on health would not be enough to achieve individual and community health, if there are not adequate structural and environmental situations to facilitate behavioral change decisions. This health promoter model for farmworkers will only be a successful strategy if environmental, organizational, and community conditions that trigger health problems are also addressed. Needs assessment previously performed among farmworkers communities [4], showed that housing, dinning and sanitary facilities conditions were also mentioned as priorities for farmworkers health, in addition to health education.

There is an urgent need for those institutions in charge of developing standards for farmworker living conditions (National Program for Farmworkers within Social Development Secretariat), to review, jointly with agribusiness, the housing, dinning and personal hygiene areas within farms as well as the labor standards regarding working conditions, wages and fair labor practices. Sustainability of our proposed health promotion model would require a joint effort from organizations such as Fair Trade, social development and health promotion institutions and agribusiness. In today's global market agribusinesses are actively looking for different types of certifications from diverse international organizations. These organizations provide an endorsement for commercialization of food in the international market through audits regarding good agricultural practices and social justice. Joint efforts between governmental institutions aiming to improve social wellbeing and health promotion (Social Development Secretariat, Health Secretariat), agribusiness, agribusiness associations, workers unions and certifying agencies, could result in overall public policies that support a joint commitment to improving health of farmworkers.

\section{Acknowledgements}

We are grateful to the PIMSA 2012-2013 Program (Research Program on Migration and Health) for the funding provided.

\section{References}

[1] Culp, K., et al. (2011) Preventing Heat-Related Illness among Hispanic Farmworkers. AAOHN Journal, 59, 23-32. http://dx.doi.org/10.3928/08910162-20101228-01

[2] Quandt, S.A., et al. (2013) Evaluating the Effectiveness of a Lay Health Promoter-Led, Community-Based Participatory Pesticide Safety Intervention with Farmworker Families. Health Promotion Practice, 14, 425-432. http://dx.doi.org/10.1177/1524839912459652

[3] Luque, J. and Castañeda, H. (2013) Delivery of Mobile Clinic Services to Migrant and Seasonal Farmworkers: A Review of Practice Models for Community-Academic Partnerships. Journal of Community Health, 38, 397-407. http://dx.doi.org/10.1007/s10900-012-9622-4

[4] Rosales, C., et al. (2012) The US/Mexico Border: A Binational Approach to Framing Challenges and Constructing Solutions for Improving Farmworkers' Lives. International Journal of Environmental Research and Public Health, 9, 2159-2174.

http://dx.doi.org/10.3390/ijerph9062159 
[5] Palacios, M., Paz, P. and Aguirre, E. (2000) Quality of Life, Environment and Health of Farmworkers from the State of Sinaloa, Mexico, in Quality of life, Health and Environment: Calidad de vida, ambiente y salud de los jornaleros agrícolas del estado de Sinaloa, in Calidad de vida, salud y ambiente: Multi-Disciplinarity Collection. In: Daltabuit, M., Mejía, J. and Alvarez, R.L., Eds., UNAM, Mexico, 301-321.

[6] The National Center for Farmworker Health (2012) Farmworkers' Health Fact Sheet Data from the National Agricultural Workers Survey.

[7] Ingram, M., et al. (2014) A Community Health Worker Intervention to Address the Social Determinants of Health through Policy Change. The Journal of Primary Prevention, 35, 119-123. http://dx.doi.org/10.1007/s10935-013-0335-y

[8] De Zapien, J.G., Ortega-Velez, M.I., Aranda, G.P., Zapien, A., Rosales, C., Taren, D., Ingram, M., Sabo, S. and Contreras, A.D. (2008) The Health of Migrant Laborers and a Model of Social Responsibility of Agricultural Enterprises. Hermosillo, Sonora, 17.

[9] Székely Pardo, M., et al. (2007) Putting Income Poverty and Inequality on the Map of Mexico. Mexican Economy. New Era, 16, 239-303.

[10] Arcury, T.A., Estrada, J.M. and Quandt, S.A. (2010) Overcoming Language and Literacy Barriers in Safety and Health Training of Agricultural Workers. Journal of Agromedicine, 15, 236-248. http://dx.doi.org/10.1080/1059924X.2010.486958

[11] Stokols, D., Allen, J. and Bellingham, R.L. (1996) The Social Ecology of Health Promotion: Implications for Research and Practice. American Journal of Health Promotion, 10, $247-$ 251. http://dx.doi.org/10.4278/0890-1171-10.4.247

[12] Richard, L., Gauvin, L. and Raine, K. (2011) Ecological Models Revisited: Their Uses and Evolution in Health Promotion over Two Decades. Annual Review of Public Health, 32, 307-326. http://dx.doi.org/10.1146/annurev-publhealth-031210-101141

[13] Israel, B.A., et al. (2001) Community-Based Participatory Research: Policy Recommendations for Promoting a Partnership Approach in Health Research. Educ Health (Abingdon), 14, 182-197. http://dx.doi.org/10.1080/13576280110051055

[14] Frieden, T.R. (2010) A Framework for Public Health Action: The Health Impact Pyramid. American Journal of Public Health, 100, 590-595. http://dx.doi.org/10.2105/AJPH.2009.185652

[15] Love, K. (2011) Little Known but Powerful Approach to Applied Research: CommunityBased Participatory Research. Geriatric Nursing, 32, 52-54. http://dx.doi.org/10.1016/j.gerinurse.2010.12.004

[16] Blumenthal, D.S. (2011) Is Community-Based Participatory Research Possible? American Journal of Preventive Medicine, 40, 386-389. http://dx.doi.org/10.1016/j.amepre.2010.11.011

[17] O’Brien, M.J., et al. (2009) Role Development of Community Health Workers: An Examination of Selection and Training Processes in the Intervention Literature. American Journal of Preventive Medicine, 37, S262-S269. http://dx.doi.org/10.1016/j.amepre.2009.08.011

[18] Patton, M.Q. (2002) Qualitative Research and Evaluation Methods. 3rd Edition, Sage, Thousand Oaks.

[19] Werner, D., Thuman, C. and Maxwell, J. (2010) Where There Is No Doctor. 2nd Edition, EEUU: The Hesperian Foundation, Berkeley.

[20] Gueguen, J., et al. (2010) Education for Health. A Practical Guide for Health Projects.

[21] Ortega, M.I., et al. (2016) Agribusiness, Corporate Social Responsibility, and Health of Agricultural Migrant Workers. Frontiers in Public Health, 4.

[22] Gofin, J. and Gofin, R. (2005) Community-Oriented Primary Care and Primary Health 
Care. American Journal of Public Health, 95, 757-757.

http://dx.doi.org/10.2105/AJPH.2004.060822

[23] Blowfield, M. and Frynas, J.G. (2005) Setting New Agendas: Critical Perspectives on Corporate Social Responsibility in the Developing World. International Affairs, 81, 499-513.

http://dx.doi.org/10.1111/j.1468-2346.2005.00465.x

[24] CSDH (2008) Closing the Gap in a Generation: Health Equity through Action on the Social Determinants of Health. Final Report of the Commission on Social Determinants of Health. World Health Organization, Geneva.

Submit or recommend next manuscript to SCIRP and we will provide best service for you:

Accepting pre-submission inquiries through Email, Facebook, LinkedIn, Twitter, etc. A wide selection of journals (inclusive of 9 subjects, more than 200 journals)

Providing 24-hour high-quality service

User-friendly online submission system

Fair and swift peer-review system

Efficient typesetting and proofreading procedure

Display of the result of downloads and visits, as well as the number of cited articles

Maximum dissemination of your research work

Submit your manuscript at: http://papersubmission.scirp.org/

Or contact jss@scirp.org 